\title{
OPTIMASI ZAT ADITIF (Apis, Citrus Aurantifolia dan Activated Charcoa) PADA PEMBUATAN SABUN ANTI JERAWAT DARI MINYAK BIJI ALPUKAT
}

\section{OPTIMIZATION OF ADDITIVES (Apis, Citrus Aurantifolia and Activated Charcoa) IN THE MAKING OF ANTI ACNE SOAP FROM AVOCADO SEED OIL}

\author{
Sukmawati, Pratiwi Putri Lestari* \\ Institut Teknologi Medan \\ *Corresponding author: pratiwiputri@itm.ac.id
}

\begin{abstract}
ABSTRAK
Sabun merupakan surfaktan yang digunakan dengan air untuk mencuci dan membersihkan. Penelitian ini dilakukan untuk melakukan uji efektifitas dari minyak biji alpukat sebagai bahan dalam pembuatan sabun transparan dan penambahan zat aditif untuk mengurangi jerawat pada wajah.Pembuatan sabun anti jerawat berbahan dasar minyak biji alpukat, $\mathrm{NaOH}$, asam stearat, gliserol, alkohol, sukrosa, zat aditif (madu, jeruk nipis dan karbon aktif), aquadest, pewarna dan pewangi. Hasil penelitian menunjukkan bahwa penambahan zat aditif yang digunakan dapat mempengaruhi kadar air dan $\mathrm{pH}$ sabun yang dihasilkan. Untuk zat aditif jenis madu dan jeruk nipis semakin banyak penambahannya maka semakin tinggi kadar air nya. Sedangkan untuk zat aditif jenis karbon aktif, semakin banyak penambahannya semakin berkurang kadar airnya, hal ini disebabkan karena karbon aktif yang digunakan berbentuk padat dan memiliki sifat mudah menyerap air. Penambahan zat aditif yang optimal diperoleh pada penambahan zat aditif madu 1 dan $3 \mathrm{ml}$ yang menghasilkan kadar air yaitu sebesar $6 \%$ dan $14 \%$ dengan pH keduanya yaitu 7 .
\end{abstract}

Kata kunci : Sabun, Zat Aditif, Saponifikasi, Biji Alpukat.

\begin{abstract}
Soap is a surfactant that is used with water for washing and cleaning. This research was conducted to test the effectiveness of avocado seed oil as an ingredient in making transparent soap and the addition of additives to reduce acne on the face. Making anti-acne soap based on avocado seed oil, NaOH, stearic acid, glycerol, alcohol, sucrose, additives (honey, lime and activated carbon), aquadest, coloring and deodorizing. The results showed that the addition of additives used could affect the water content and $\mathrm{pH}$ of the soap produced. For additives honey and lime the more additions, the higher the water content. As for the additive type of activated carbon, the more additions the less water content, this is because the activated carbon used is solid and has the property of easily absorbing water. Optimal addition of additives
\end{abstract}


was obtained from the addition of honey additives 1 and $3 \mathrm{ml}$ which produced a moisture content of $6 \%$ and $14 \%$ with a pH of both, 7 .

Keywords : Soap, Additives matter, Saponification, Avocado seed.

\section{PENDAHULUAN}

Produksi alpukat di Indonesia cukup tinggi, hal ini dapat dibuktikan dengan data produksi buah alpukat di Indonesia pada tahun 2014 dari Badan Pusat Statistik (BPS) yaitu mencapai 307.326 ton per tahun. Dari data BPS, produksi alpukat di Indonesia terus meningkat setiap tahunnya, seiring dengan meningkatnya produksi alpukat, maka limbah biji alpukat yang dihasilkan juga meningkat. Oleh karena itu, perlu penanganan terhadap limbah biji alpukat dengan dilakukan penelitian mengenai biji alpukat.

Biji alpukat terdiri dari 65\% daging buah (mesokarp), 20\% biji (endocarp), dan 15\% kulit buah (perikarp). Menurut Prasetyowati, biji alpukat mengandung $15-20 \%$ minyak. Biji alpukat mengandung minyak yang hampir sama dengan kedelai sehingga biji alpukat dapat dijadikan sebagai sumber minyak nabati. Penggunaan sabun di kehidupan sehari- hari sangatlah penting, hampir setiap hari kegiatan kita menggunakan sabun seperti mandi, mencuci dan masih banyak lagi. Sabun merupakan surfaktan yang digunakan dengan air untuk mencuci dan membersihkan. Sabun dihasilkan dari proses saponifikasi yaitu hidrolisis lemak menjadi asam lemak dan gliserol dalam kondisi basa. Oleh karenan itu, biji alpukat seharusnya dapat diolah kembali menjadi sebuah produk atau bahan baku yang bermanfaat dengan pembuatan sabun menggunakan minyak biji alpukat.

Penelitian ini dilakukan untuk melakukan uji efektifitas dari minyak biji alpukat sebagai bahan dalam pembuatan sabun transparan dan penambahan zat aditif untuk mengurangi jerawat pada wajah. Ekstrasi biji alpukat dilakukan dengan cara destilasi.

\section{METODE PENELITIAN}

\subsection{Bahan dan Alat}

Variabel dan Kondisi Proses

- Variabel tetap proses:

- Minyak biji alpukat

- Larutan $\mathrm{NaOH}$

- Asam stearat

- Alkohol

- Gliseri

- Variabel berubah proses:

- Zat aditif (madu, jeruk nipis dan karbon aktif) $=1 \mathrm{ml}, 3 \mathrm{ml}, 5 \mathrm{ml}$ dan $7 \mathrm{ml}$.

\section{Alat}

Alat-alat yang digunakan antara lain : Klem, Thermometer, Batang pengaduk, Statif, Beaker glasss, Waterbath.

\section{Bahan}

Bahan - bahan yang dibutuhkan adalah minyak biji alpukat, larutan $\mathrm{NaOH}$, asam stearat, alkohol, gliserin dan zat aditif (madu, jeruk nipis dan karbon aktif).

\subsection{Prosedur Penelitian}


Minyak biji alpukat dipanaskan lalu menambahkan natrium hidroksida kemudian asam stearat, alkohol, gliserin, dan larutan gula. Campuran dihomogenkan sambil terus dipanaskan selama beberapa menit, kemudian memasukkan zat aditif, pewangi dan pewarna. Setelah campuran homogen lalu dimasukkan kedalam cetakan kemudian didinginkan selama satu hari.

Analisa yang dilakukan adalah analisa kadar Asam lemak bebas, analisa kadar air, analisa pH dan analisa organoleptik.

Variabel yang dipelajari meliputi penambahan zat aditif Madu, Jeruk nipis dan karbon aktif dengan variasi $1 \mathrm{ml}, 3 \mathrm{ml}, 5 \mathrm{ml}$ dan $7 \mathrm{ml}$.

\subsection{Hasil Penelitian}

\section{HASIL DAN PEMBAHASAN}

Tabel 1. Hasil Standarisasi $\mathrm{NaOH}$

\begin{tabular}{ccc}
\hline $\begin{array}{c}\text { Volume } \\
\mathrm{NaOH}(\mathrm{ml})\end{array}$ & $\begin{array}{c}\text { Volume Asam } \\
\text { Oksalat }(\mathrm{ml})\end{array}$ & $\begin{array}{c}\text { Normalitas } \\
\mathrm{NaOH}(\mathrm{N})\end{array}$ \\
\hline 10 & 0,9 & 0,0252 \\
\hline 10 & 1,4 & 0,0392 \\
\hline 10 & 1,9 & 0,0532 \\
\hline
\end{tabular}

Tabel 2. Hasil Kadar Asam Lemak Bebas

\begin{tabular}{ccc}
\hline $\begin{array}{c}\text { Volume Asam } \\
\begin{array}{c}\text { Lemak Bebas } \\
(\mathrm{ml})\end{array}\end{array}$ & $\begin{array}{c}\text { Volume Natrium } \\
\text { Hidroksida } \\
(\mathrm{ml})\end{array}$ & $\begin{array}{c}\text { Kadar Asam Lemak } \\
\text { Bebas } \\
(\%)\end{array}$ \\
\hline 15 & 0,7 & 1,221 \\
\hline 15 & 0,6 & 1,046 \\
\hline 15 & 0,4 & 0,697 \\
\hline
\end{tabular}

Tabel 3. Tabel Analisa Kadar Air dan pH pada penambahan zat aditif

\begin{tabular}{cccc}
\hline Zat aditif & $\begin{array}{c}\text { Volume } \\
(\mathrm{ml})\end{array}$ & $\begin{array}{c}\text { Kadar air } \\
(\%)\end{array}$ & $\mathrm{pH}$ \\
\hline \multirow{3}{*}{ Madu } & 1 & 6 & 7 \\
\cline { 2 - 4 } & 3 & 14 & 7 \\
\cline { 2 - 4 } & 5 & 20 & 7 \\
\hline \multirow{3}{*}{ Jeruk } & 7 & 18 & 8 \\
\cline { 2 - 4 } nipis & 1 & 18 & 9 \\
\cline { 2 - 4 } & 3 & 18 & 8 \\
\hline Karbon & 5 & 48 & 9 \\
\hline & 7 & 42 & 8 \\
\hline
\end{tabular}




\begin{tabular}{cccc}
\hline aktif & 3 & 10 & 8 \\
\cline { 2 - 4 } & 5 & 8 & 9 \\
\cline { 2 - 4 } & 7 & 10 & 9 \\
\hline
\end{tabular}

Tabel 4. Tabel analisa organoleptik

\begin{tabular}{|c|c|c|c|c|c|c|c|c|c|c|c|c|}
\hline \multirow{2}{*}{ Organoleptik } & \multicolumn{4}{|c|}{ Madu } & \multicolumn{4}{|c|}{ Jeruk nipis } & \multicolumn{4}{c|}{ Karbon aktif } \\
\cline { 2 - 12 } & $\mathrm{H}_{1}$ & $\mathrm{H}_{3}$ & $\mathrm{H}_{5}$ & $\mathrm{H}_{7}$ & $\mathrm{H}_{1}$ & $\mathrm{H}_{3}$ & $\mathrm{H}_{5}$ & $\mathrm{H}_{7}$ & $\mathrm{H}_{1}$ & $\mathrm{H}_{3}$ & $\mathrm{H}_{5}$ & $\mathrm{H}_{7}$ \\
\hline Bentuk & P & P & P & P & P & P & P & P & P & P & P & P \\
\hline Bau & PK & PK & PK & PK & JN & JN & JN & JN & PK & PK & PK & PK \\
\hline Warna & C & C & C & C & HT & HT & HT & HT & H & H & H & H \\
\hline Pemisahan & TA & TA & TA & TA & TA & A & A & A & TA & A & A & A \\
\hline
\end{tabular}

Keterangan :
$\mathrm{H}_{1}$ : Hari Pertama
$\mathrm{H}_{3}$ : Hari Ketiga
$\mathrm{H}_{5}$ : Hari Kelima
$\mathrm{H}_{7}$ : Hari Ketujuh
$\mathrm{P}$ : Padat
PK : Permen Karet
JN : Jeruk Nipis
$\mathrm{C}$ : Coklat
HT : Hijau Transparan
$\mathrm{H}$ : Hitam
TA : Tidak Ada
A : Ada

\subsection{Pembahasan}

\subsubsection{Pengaruh penambahan zat aditif terhadap kadar air produk}

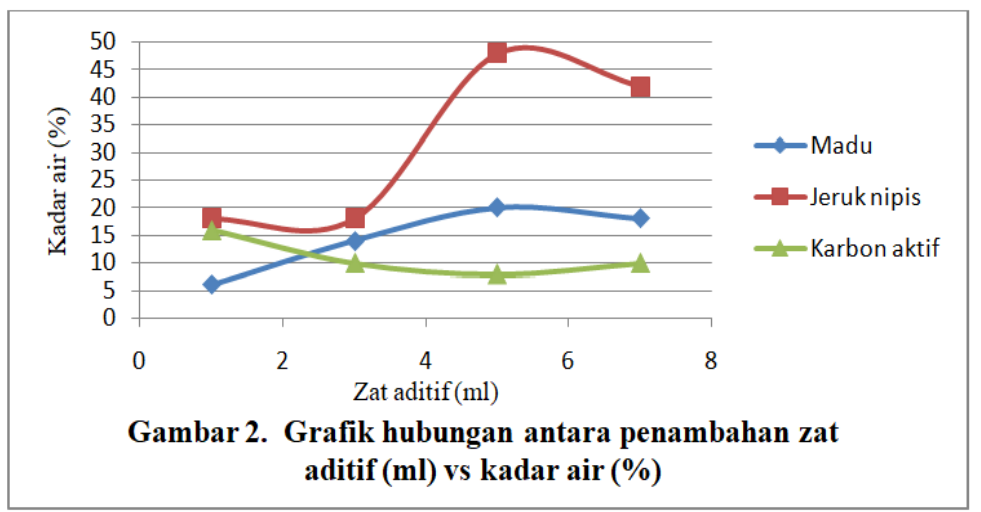


Pengaruh penambahan zat aditif (madu, jeruk nipis dan karbon aktif) terhadap produk yang dihasilkan dapat dilihat pada gambar 2. Pada gambar dapat dilihat bahwa terdapat hasil sabun optimum dengan adanya penambahan zat aditif pada akhir reaksi saponifikasi. Semakin banyak zat aditif yang ditambahkan Untuk kondisi optimum dalam pembuatan sabun adalah pada penambahan madu (1 dan $3 \mathrm{ml})$ dan penambahan karbon aktif $(3,5$ dan $7 \mathrm{ml})$. Pada penambahan zat aditif madu dan karbon aktif dengan volume tersebut, kadar air dalam reaktan sedikit dibanding pada penambahan madu (5 dan $7 \mathrm{ml}$ ), Jeruk nipis $(1,3,5$ dan $7 \mathrm{ml}$ ) dan karbon aktif $1 \mathrm{ml}$. Karena pada dasarnya sabun memiliki kadar air yang sedikit. Pada grafik diatas dapat dilihat perbedaan kuantitas sabun yang dihasilkan cukup signifikan pada penambahan madu (5 dan $7 \mathrm{ml}$ ) dihasilkan kadar air $20 \%$ dan $18 \%$ kemudian pada penambahan jeruk nipis $(1,3,5$, dan $7 \mathrm{ml})$ sabun yang dihasilkan memiliki kadar air 18\%, 18\%, 48\% dan $42 \%$ lalu pada penambahan karbon aktif $1 \mathrm{ml}$ sabun yang dihasilkan memiliki kadar air $16 \%$, dan hasil sabun yang paling optimum yaitu pada penambahan madu $1 \mathrm{ml}$ dan $3 \mathrm{ml}$ dihasilkan kadar air 6\%, dan 14\% dan pada penambahan karbon aktif (3, 5 dan $7 \mathrm{ml}$ ) dihasilkan kadar air 10\%, 8\%, dan 10\%. Selain kuantitasnya cukup tinggi, sabun yang dihasilkan juga mempunyai kualitas yang baik. Bentuknya sangat padat karena kadar airnya cukup sedikit dan mendekati standar baku mutu dari SNI.

Dari hasil penelitian pembuatan sabun yang dilakukan didapati hasil optimum pada penambahan madu 1 dan $3 \mathrm{ml}$ serta penambahan karbon aktif 1, 5 dan $7 \mathrm{ml}$, diperoleh hasil yang sesuai dengan standar mutu sabun SNI 3532:2016 (Standart Nasional Indonesia,2016) yang menyatakan bahwa kadar air maksimal $15 \%$ hal ini sesuai dengan hasil yang diperoleh dimana kadar airnya masih berada dalam standar mutu sabun.

Hal ini dikarenakan pada akhir reaksi saponifikasi, banyaknya penambahan zat aditif harus disesuaikan dengan banyaknya bahan baku pembuatan sabun itu sendiri. Kadar air sabun yang baik juga dipengaruhi oleh jenis zat aditif apa yang akan ditambahkan. Untuk zat aditif jenis madu dan jeruk nipis semakin banyak penambahannya maka semakin tinggi kadar air nya. Sedangkan untuk zat aditif jenis karbon aktif, semakin banyak penambahannya semakin berkurang kadar airnya, hal ini disebabkan karena karbon aktif yang digunakan berbentuk padat dan memiliki sifat mudah menyerap air. Hasil analisa sabun memiliki kadar air sekitar 6\% hingga 15\%. Dilakukan pada suhu $105^{\circ} \mathrm{C}$ selama 2 jam, diperkirakan pada kondisi ini air yang terkandung dalam sabun menguap sehingga air (kelembaban) dapat diminimalkan.

\subsubsection{Pengaruh penambahan zat aditif terhadap keasaman (pH) sabun}

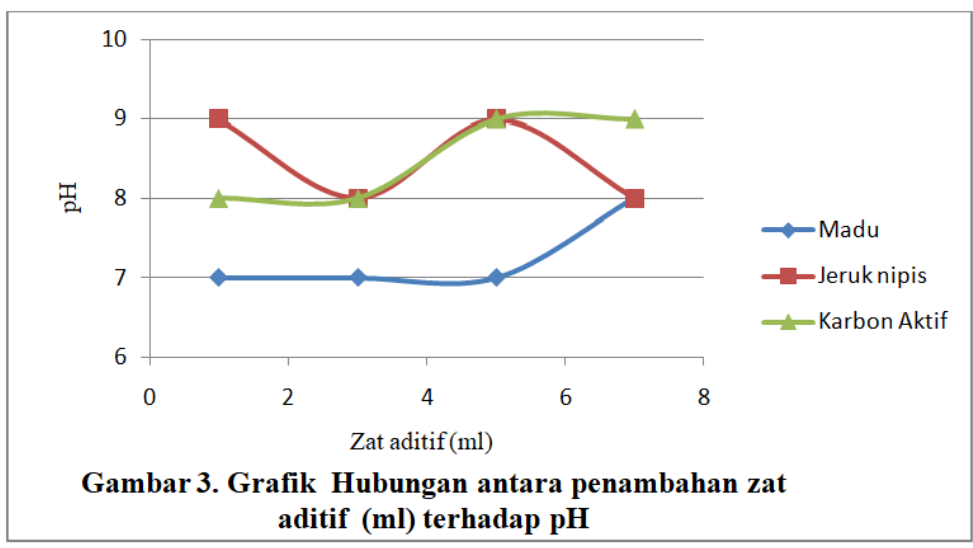


Nilai derajat keasaman $(\mathrm{pH})$ yang paling baik dimiliki oleh sabun komersil kecantikan lokal dengan pH 7 sedangkan sabun komersil kesehatan lainnya memiliki pH 8-9 (>7). Sabun dengan pH netral merupakan sabun yang baik, karena lembut untuk kulit. Hasil analisa untuk sabun padat memiliki $\mathrm{pH}$ sekitar 6-8. Hasil diatas menunjukkan bahwa nilai $\mathrm{pH}$ sabun padat yang dihasilkan dengan penambahan zat aditif (madu, jeruk nipis dan karbon aktif) cukup baik. Menurut Wasitaatmaja (1997), $\mathrm{pH}$ yang sangat tinggi atau rendah dapat meningkatkan daya absorbsi kulit sehingga kulit menjadi iritasi. Hal ini sesuai dengan standar mutu SNI no 3532-2016 yang menyatakan bahwa kelembaban sabun harus berada pada kadar $\mathrm{pH}$ dari kondisi netral hingga basa. Penambahan zat aditif dilakukan untuk menambah nilai mutu sabun.

\subsubsection{Pembahasan hasil analisa kadar asam lemak bebas (Free Fatty Acid)}

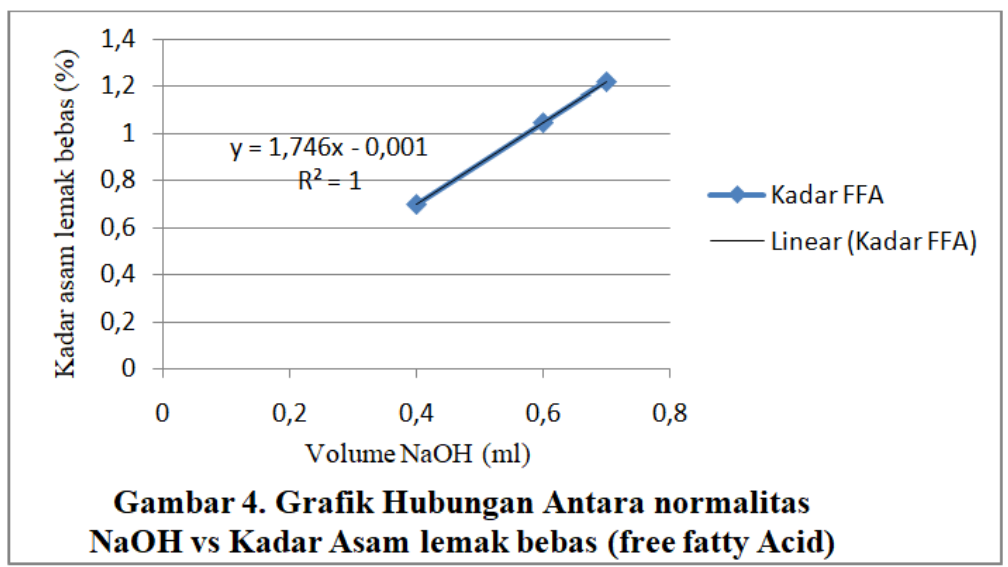

Pada pembuatan sabun asam lemak bebas harus dihilangkan. Dalam proses hidrolisis, minyak/ lemak akan diubah menjadi asam-asam lemak bebas. Maka terjadilah proses hidrolisis oleh $\mathrm{NaOH}$ yang akan menghilangkan asam lemak bebas. Proses hidrolisis dapat mengakibatkan kerusakan pada minyak/ lemak karena terdapatnya sejumlah air pada minyak/lemak tersebut. Proses ini dapat menyebabkan terjadinya Hydrolitic Rancidity yang menghasilkan aroma dan rasa tengik pada minyak/lemak. Dan akhirnya akan menimbulkan bau yang tidak disenangi karena adanya proses oksidasi oleh asam lemak tersebut, kadar asam lemak yang tinggi akan meningkat, bau tengik dan lemak yang akan keluar dari sabun tersebut. Dan pada penelitian ini didapati hasil kadar FFA paling tinggi sebesar 1,221 \%, hal ini sesuai dengan baku mutu SNI nomor 06-3532-2016 bahwa kadar FFA tidak boleh lebih dari 2,5\% fraksi massa. (StandarNasional Indonesia,2016).

\subsubsection{Pembahasan Analisa Uji Organoleptik}

Uji Organoleptik yang dilakukan untuk melihat adanya perubahan pada bentuk sediaan selama penyimpanan. Dari tabel 4.7 dapat dilihat bahwa hasil pengujian semua formula tidak mengalami perubahan bentuk, bau dan warna. Tetapi pada pengujian pemisahan, penambahan zat aditif madu dari hari pertama pengujian hingga hari ketujuh tidak mengalami pemisahan sedangkan penambahan zat aditif jeruk nipis dan karbon aktif pada hari pertama tidak mengalami pemisahan tetapi pada hari ketiga hingga hari ketujuh mengalami pemisahan dimana pada sabun dengan penambahan jeruk nipis, terdapat cairan yang kami simpulkan sebagai air jeruk nipis yang tidak menyatu sempurna dengan sabun. Sedangkan pada sabun dengan penambahan karbon aktif mengalami pemisahan, dimana karbon aktifnya mengendap dibagian bawah sabun. Hal ini disebabkan karena perbandingan zat aditif jeruk nipis dan karbon aktif yang ditambahkan tidak 
sebanding dengan banyaknya bahan baku yang digunakan, sehingga lebih banyak zat aditif dari pada sabun itu sendiri.

Busa yang dihasilkan pada pembuatan sabun anti jerawat dengan penambahan zat aditif (madu, jeruk nipis dan karbon aktif) tidak sama. Dimana semakin banyak volume zat aditif yang digunakan maka busa yang dihasilkan semakin sedikit.

\section{KESIMPULAN}

Pada penambahan zat aditif untuk analisa kadar air diperoleh kesimpulan bahwa penambahan zat aditif jenis madu lebih optimal dan menghasilkan sabun anti jerawat yang baik. Bahan baku (minyak biji alpukat) yang digunakan pada pembuatan sabun anti jerawat memiliki kadar asam lemak bebas paling tinggi yaitu 1,221\%, hal ini sesuai dengan baku mutu SNI nomor 06-3532-2016 bahwa kadarasam lemak bebas (FFA) tidak boleh lebih dari 2,5\%. Sabun anti jerawat dengan penambahan zat aditif optimum yang dihasilkan diperoleh dari penambahan zat aditif jenis madu dengan volume $1 \mathrm{ml}$, dengan karaktristik sebagai berikut : kadar air: $6 \%$, pH: 7, Organoleptik : tidak mengalami perubahan bentuk, warna, bau dan tidak terjadi pemisahan.

\section{DAFTAR PUSTAKA}

Aldi, dkk. 2016. Adsorbsi Minyak Jelantah Menggunakan Karbon Aktif dan Serbuk Kopi Pada Pembuatan Sabun Padat Ramah Lingkungan. Politeknik Harapan Bersama. Tegal

Anonym, 1987. Pembuatan Biodiesel dari minyak biji alpukat. Instititut Teknologi Medan : Medan. Brown, G.G, Katz D, Foust A.S, Schneidewind S, 1973, Unit Operation, John Wiley \& Sons, Inc, Tokyo.

Diah, Pramushinta. 2012. Pembuatan Sabun. http://PembuatanSabun_Inuyashaku's Blog.html

Dilla, dkk. 2016. Optimasi Komposisi Bahan Baku dan Kecepatan Pengadukan Pada Pembuatan Sabun Transparan Dari Minyak Biji Alpukat. ITM.

Fatimah. 2018. Pembuatan Sabun Padat Madu dengan Penambahan Ekstrak Kunyit (Curcuma Domestica). Politeknik Negeri Tanah Laut. Kalimantan Selatan

Fessenden \& Fessenden. 1982. Sejarah Sabun Mandi Kimia Organik Jilid 1. Jakarta: Erlangga. Herbamart

Hui, Y. H, 1996, Bailey's Industrial Oil and Fat Products, fifth edition, New York, Jhon Willey \& Sons Inc http://www.alcasoft.com/ soapfact/ history.html

Irdoni, HS dan Nirwana, HZ. 2013. Modul Praktikum Kimia Organik. Laboratorium Teknologi Bahan Alam \& Mineral Teknik Universitas Riau, Pekanbaru

Jannah, Barlianty. 2009. Sifat Fisik Sabun Transparan dengan Penambahan Madu pada Konsentrasi yang berbeda. ITB. Bogor

Perry, R. H , 1997. Perry's Chemical engineers Handbook,7 edition. Mc Graw Hill Company. NewYork

Ralph J. Fessenden, 1992. Kimia Organik Jilid 2. 8 eks. Jakarta: Erlangga

Sulastri, dkk. Formulations Transparent Soap Solid Lime Juice (Citrus Aurantifolia Swingle). Akademi Farmasi Muhammadiyah. Cirebon

Svehla, G. 1979. Text Book of Macro and Semimicro Qualitative Inorganic Analysis.

Vogel, 1985. Buku Teks Analisis Anorganik Kualitatif Makro dan Semimikro Bagian 1. Jakarta: PT Kalman Media Pustaka 